\title{
Analisis Intensitas Citra Tetesan Air dengan Metode Laser Speckle Imaging
}

\author{
Feri Helmi Basri", Harmadi, Marzuki \\ Jurusan Fisika FMIPA Universitas Andalas \\ Kampus Unand, Limau Manis, Padang, 25163 \\ *ferihelmi@gmail.com
}

\begin{abstract}
ABSTRAK
Analisis nilai intensitas citra tetesan air dengan metode Laser Speckle Imaging telah dilakukan. Penelitian ini menggunakan sistem perancangan forward-scattering. Sistem terdiri dari tiga unit yaitu transmitter sebagai sumber cahaya menggunakan laser He-Ne, receiver sebagai detektor menggunakan CCD (Charge Couple Device), dan penampil menggunakan PC. Transmitter dan receiver diposisikan sejajar dengan jarak yang telah diatur agar berkas cahaya laser menyinari detektor CCD pada sudut $0^{0}$ untuk mendapatkan citra spekel. Intensitas citra spekel dikarakterisasi menggunakan 6 manik-manik dengan diameter berbeda $(2,15-11,91 \mathrm{~mm})$. Nilai intensitas citra spekel tertinggi didapatkan pada diameter manik-manik 2,15 mm yaitu 254,62 a.u dan terendah pada manik-manik 11,91 mm yaitu 224,5 a.u. Hasil karakteriasi menunjukkan bahwa intensitas citra spekel menurun ketika objek yang terdeteksi berukuran lebih besar. Hasil yang sama juga didapatkan menggunakan tetesan air dari tabung yang berlubang dengan diameter 1-7 mm. Citra spekel tetesan air dianalisis menggunakan fungsi autokorelasi untuk mendapatkan ukuran bulir spekel. Ukuran bulir spekel terbesar didapatkan pada diameter lubang tetesan 6 $\mathrm{mm}$ yaitu $856,87 \mu \mathrm{m}$ dan terkecil didapatkan pada diameter lubang tetesan $1 \mathrm{~mm}$ yaitu 198,15 $\mu \mathrm{m}$. Hasil yang diperoleh menunjukkan bahwa semakin besar tetesan air, maka nilai intensitas citra spekel menurun dan ukuran bulir spekel membesar.

Kata kunci : citra, forward-scattering, gray scale, laser He-Ne, ukuran bulir spekel
\end{abstract}

\begin{abstract}
The image intensity of water drop has been analyzed using forward-scattering Laser Speckle Imaging. The system consists of three units, namely, the transmitter as a light source using the He-Ne laser, the receiver as a detector using CCD (Charge Couple Device), and the display using a PC. The transmitter and receiver were positioned parallel to set the distance so that the laser light beam illuminated the CCD detector at an angle of $0^{\circ}$ to obtain a speckle image. Prior to analyzing the image intensity of water drop, the speckle image intensity of 6 different beards was examined. The highest speckle image intensity value was 254.62 a.u for the diameter of $2.15 \mathrm{~mm}$, and the lowest value was 224.5 a.u for the diameter of 11.91 $\mathrm{mm}$. Thus, the intensity of the speckle image decreases with increasing the object size. The same patterns were also obtained using water drops from a hollow tube with the diameter of $1-7 \mathrm{~mm}$. The largest grain size of speckle image was $856.87 \mu \mathrm{m}$ at the hollow diameter of $6 \mathrm{~mm}$ and the smallest grain was 198.15 $\mu \mathrm{m}$ at the hollow diameter of $1 \mathrm{~mm}$. Thus, if water droplet size, which is indicated by the hollow size, increases, the speckle image intensity decreases and on the other hand, the grain size of speckel increases Keywords: image, forward-scattering, gray scale, laser He-Ne, grain size of speckel
\end{abstract}

\section{PENDAHULUAN}

Pengukuran curah hujan sangat penting untuk penyusunan suatu rancangan pemanfaatan air, rancangan pengendalian banjir (Permana dkk., 2015) serta untuk mengetahui penyebab bendungan rusak (Sawant dan Ghonge, 2015). Pada umumnya curah hujan diukur dari parameter butiran hujan (Kolte dan Ghonge, 2016). Pengukuran curah hujan dapat dilakukan dengan teknik optical seperti teknik hamburan dan teknik pencitraan (Löffler-Mang dan Joss, 2000).

Metode LSI (Laser Speckle Imaging) adalah salah satu teknik pencitraan optik-laser yang mendeteksi dan menganalisis perubahan intensitas dari objek yang terhambur (Tamaki dkk., 1994). Metode LSI memiliki kesederhanaan dalam sistem perancangannya yang terdiri dari tiga komponen utama yaitu laser sebagai sumber cahaya, objek pengamatan dan CCD sebagai detektor (Erlangga, 2014). CCD merupakan rangkain yang telah terintegrasi dan memiliki kelebihan pada data pengamatan berupa sinyal digital dalam bentuk citra sehingga memiliki pencitraan penuh, akuisisi data langsung, akurat, kuantitatif dan biaya rendah (Harmadi, 2012). Selain itu, metode LSI ini dapat mengukur citra spekel pada objek hingga mikrometer dengan 
program autokorelasi matlab. Program autokorelasi ini mengukur bulir spekel secara keseluruhan sehingga diperoleh nilai rata-rata (Muchlian dkk., 2013).

Sistem perancangan metode LSI pada penelitian ini menggunakan pendekatan forwardscattering. Pada penelitian sebelumnya Chicea (2007) melakukan percobaan hamburan cahaya koheren melalui pendekatan forward scattering dengan variasi konsentrasi partikel. Hasil yang didapatkan adalah ukuran spekel berkurang dan kontras menurun saat konsentrasi partikel meningkat. Hasil yang sama juga didapatkan oleh Wang dkk (2014) menggunakan konsep interferometer michelson.

Berdasarkan hasil penelitian spekel yang telah dilakukan sebelumnya, metode LSI dapat digunakan untuk mengukur hujan berdasarkan parameter seperti butiran hujan. butiran hujan dimodelkan sebagai tetesan air dari tabung berlubang dengan variasi diameter $1 \mathrm{~mm}, 2$ $\mathrm{mm}, 3 \mathrm{~mm}, 4 \mathrm{~mm}, 5 \mathrm{~mm}, 6 \mathrm{~mm}$ dan $7 \mathrm{~mm}$. Lubang pada tabung air dibuat menggunakan bor 1 $\mathrm{mm}-7 \mathrm{~mm}$. Ukuran dibuat bervariasi berdasarkan ukuran butiran hujan 0,3 mm-7 mm. Berdasarkan hasil penelitian (Marzuki dkk., 2010; 2013), butiran yang lebih besar, misalnya > $10 \mathrm{~mm}$ akan pecah menjadi butiran yang lebih kecil. Selain itu, butiran hujan yang lebih kecil dari $1 \mathrm{~mm}$, akan sulit diamati. Untuk tahap awal digunakan tetesan air untuk menganalisis pola spekel yang terbentuk dari cahaya terhambur saat disinari berkas laser. Pola spekel yang terbentuk direkam menggunakan CCD untuk melihat perubahan nilai intensitas citra spekel dan ukuran bulir spekel.

\section{METODE}

\subsection{Alat dan Bahan}

Alat dan bahan yang digunakan pada penelitian ini terdiri dari laser He-Ne continuous wave 632,8 nm sebagai sumber cahaya, detektor CCD (Charge Couple Device) 480 x 640 piksel 30 fps (frame per second),lensa cekung \& lensa plan-convex digunakan sebagai beam expander, lensa cembung, manik-manik, akrilik, tabung berlubang dan pipa housing.

\subsection{Perancangan Sistem LSI (Laser Speckle Imaging)}

Sistem rancang bangun pada metode LSI terdiri dari transmitter sebagai sumber cahaya koheren dan receiver sebagai detektor. Sumber cahaya koheren yang digunakan, yaitu sinar laser He-Ne seri 1507P-1 dengan $\lambda=632,8 \mathrm{~nm}$ dengan daya keluaran 0,8 mW. Beam expander diposisikan di depan laser He-Ne untuk memperbesar berkas laser. Sebagai detektor adalah CCD kamera $30 \mathrm{fps}$ (frame per second) yang terhubung dengan PC (personal computer). Housing digunakan pada transmitter dan receiver sebagai pelindung. Transmitter diposisikan sejajar dengan receiver pada sudut $\pm 0^{0}$ terhadap berkas cahaya laser agar CCD menerima informasi secara langsung. Jarak antara transmitter dan receiver didapatkan melalui karakterisasi berkas cahaya laser. Receiver dihubungkan ke PC sebagai penampil. Analisis perubahan nilai intensitas citra dari pola spekel yang terbentuk menggunakan objek manikmanik dan tetesan air. Bentuk susunan alat dan bahan pada Gambar 1.

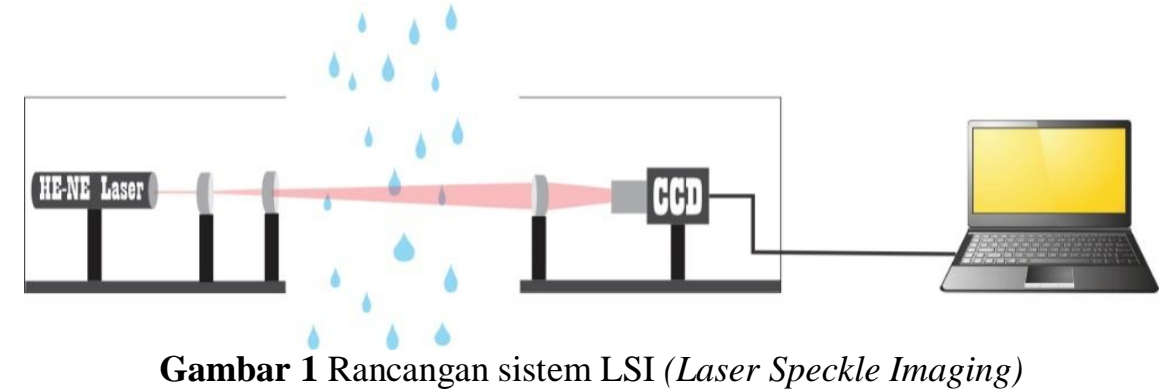

\subsection{Pengolahan Citra Pola Spekel}

Pola gelap terang dari spekel terjadi karena frekuensi yang berbeda, dimana pola gelap lebih dominan dari pada pola terang. Berdasarkan deskripsi tentang statistik distribusi intensitas yang dihasilkan oleh spekel, diasumsikan bahwa medan yang koheren dengan panjang 
gelombang menerangi permukaan suatu bahan. Panjang gelombang yang dipilih memiliki ukuran yang lebih kecil dari bahan yang digunakan (Rabal dan Braga, 2009).

Pola spekel yang diperoleh dapat diolah dengan menggunakan pengolah citra melalui karakteristik histrogram intensitas gray level (tingkat keabu-abuan) dari citra. Karakteristik histogram diperoleh dalam bentuk tampilan distribusi intensitas citra tingkat keabu-abuan yang bervariasi disetiap titik di dalamnya, sehingga dapat ditentukan nilai rerata intensitas $\langle l\rangle$ citra spekel. Perubahan nilai intensitas ini yang akan digunakan untuk membedakan intensitas citra tanpa tetesan air dan citra saat tetesan air jatuh seperti yang terlihat pada Gambar 2.

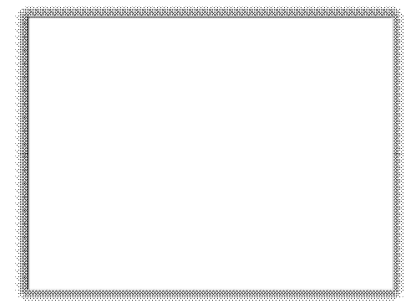

(a)

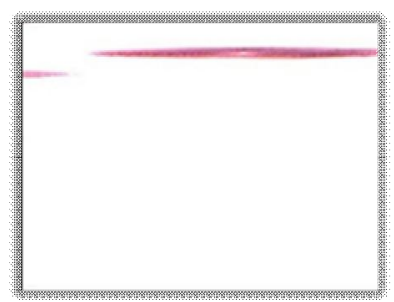

(b)

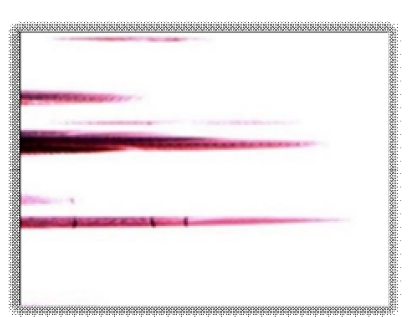

(c)

Gambar 2 (a) Citra spekel sebelum tetesam air, (b) Tetesan air tabung $1 \mathrm{~mm}$, dan (c)

Tetesan air tabung $2 \mathrm{~mm}$

\subsection{Analisis Ukuran Bulir Spekel}

Perhitungan ukuran bulir spekel dilakukan dengan fungsi autokolerasi menggunakan software Matlab R2017a. Hasil running program matlab fungsi autokorelasi terlihat seperti Gambar 3. Metode ini didasarkan pada integrasi citra dengan dirinya sendiri. Citra pola spekel yang terekam adalah 480 × 640 piksel. Selanjutnya dilakukan autokolerasi yang menghasilkan puncak maksimum untuk menghitung FWHM-nya sehingga diperoleh ukuran piksel bulir dalam dua arah (horizontal dan vertikal) seperti yang terlihat pada Gambar 3b dan 3c. Terakhir dilakukan evaluasi ukuran spekel dalam arah horizontal dan vertikal yang kemudian dikonversi ke dalam satuan mikron ( 1 piksel $=5$ mikron $)$. Ukuran satu piksel didapat dari spesifikasi kamera yang digunakan.

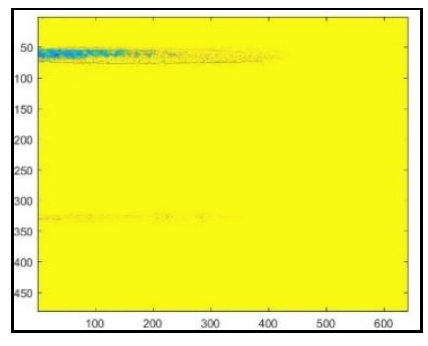

A

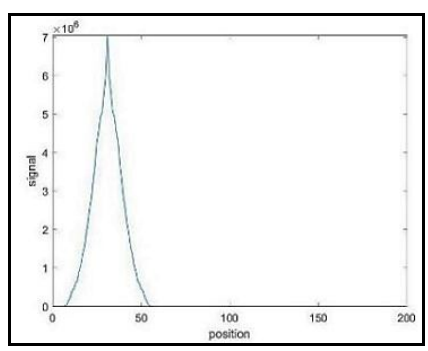

$\mathrm{C}$

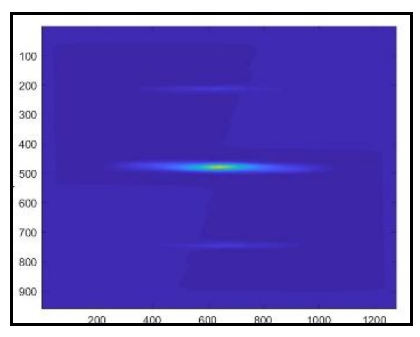

B

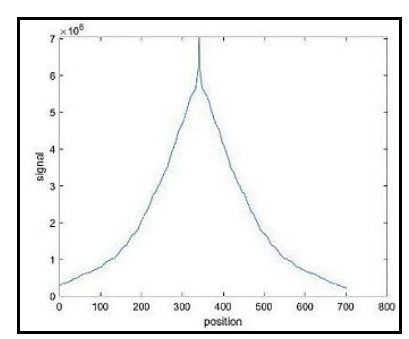

D

Gambar 3 Hasil running autokorelasi matlab (a) Citra ukuran 480x640 piksel (b) Fungsi autokorelasi citra (c) Plot pusat fungsi autokorelasi arah vertikal (d) Plot pusat fungsi autokorelasi arah horizontal 


\section{HASIL DAN DISKUSI}

\subsection{Karakterisasi Intensitas Citra Spekel}

Karakterisasi nilai intensitas citra spekel dilakukan untuk mengetahui perubahan nilai intensitas citra spekel yang direkam oleh CCD saat objek melewati berkas cahaya laser. Benda yang digunakan untuk karakterisasi ini menggunakan manik-manik dengan ukuran yang telah diketahui. Variasi ukuran manik-manik yang digunakan sebanyak 6 buah mulai dari 2,15 mm ; 4,46 mm ; 5,91 mm ; 7,88 mm ; 9,86 mm ; 11,91 mm. Pengambilan data karakterisasi dari manik-manik dilakukan sebanyak 20 kali untuk masing-masing ukuran. Nilai rata-rata dari 20 data untuk masing-masing ukuran digunakan untuk analisa perubahan intensitas citra.

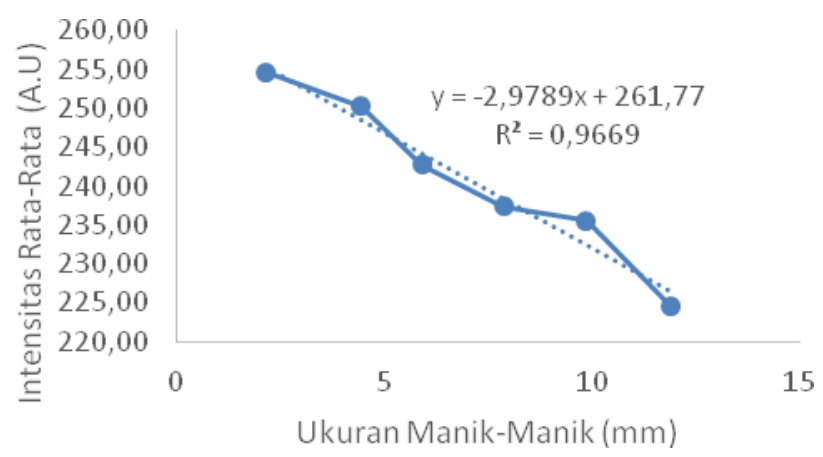

Gambar 4 Perubahan Nilai Intensitas Citra Spekel terhadap ukuran diameter manik-manik

Pada Gambar 4 dapat dilihat bahwa nilai intensitas rata-rata citra spekel berkolerasi sangat kuat dengan ukuran manik-manik, yang terlihat dari nilai koefisien determinasi yang tinggi yaitu $R^{2}=0,9669$. Semakin besar ukuran benda yang digunakan saat melewati berkas cahaya laser, maka nilai intensitas citra spekel semakin menurun seperti yang terlihat dari koefisien slope persamaan regresi yang bernilai negatif. Kondisi ini sama dengan perubahan intensitas laser pada parsivel (Loffler-Mang dan Jos, 2000).

\subsection{Korelasi Intensitas Citra Spekel dengan Ukuran Bulir Spekel}

Prosedur tahap pengolahan citra untuk memperoleh nilai intensitas yaitu menyiapkan pola spekel dalam bentuk citra video.avi 640 x 480 piksel hasil pencitraan spekel dengan LSI. Lalu mengkonversi warna asli video RGB menjadi skala keabu-abuan menggunakan program citra ImageJ. Pola spekel yang diperoleh membawa informasi fisis dengan variasi acak dalam suatu intensitas citra tingkat keabu-abuan yang nilainya berkisar dari 0 sampai 255 . Menganalisis variasi acak pola spekel secara statistik menggunakan program pengolahan citra ImageJ.

Pengujian tetesan air dilakukan menggunakan laser He-Ne sebagai sumber cahaya dengan sinar berkas yang diperbesar menggunakan beam expander. Pengujian dilakukan dengan merekam tetesan air untuk setiap tabung selama 15 detik. Dengan demikian dari rekaman video tersebut akan didapatkan intensitas rata-rata selama 15 detik dengan menggunakan program ImageJ. Rekaman video tetesan air juga akan di ekstrak kedalam bentuk frame, dengan spesifikasi kamera 30 frame/second untuk mendapatkan nilai intensitas citra masing-masing frame

Rekaman video yang berupa citra pola spekel dikonversi menjadi grayscale untuk memperoleh karakteristik histogram. Karakteristik histogram dalam bentuk tampilan distribusi intensitas citra tingkat keabu-abuan yang bervariasi disetiap titik di dalamnya, sehingga dapat ditentukan nilai rerata intensitas $\langle I\rangle$. Perubahan nilai intensitas ini yang akan digunakan untuk membedakan intensitas citra. 


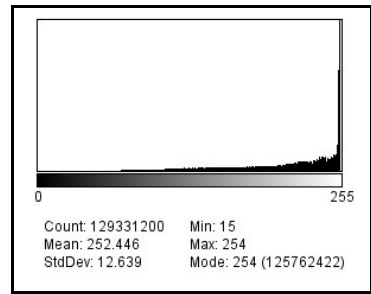

(a)

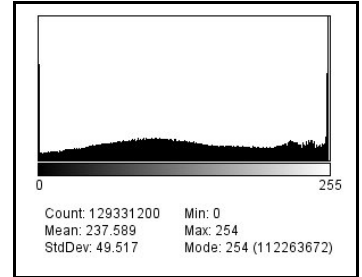

(d)

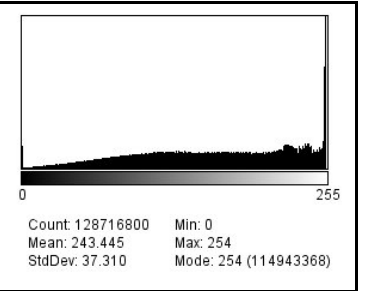

(b)

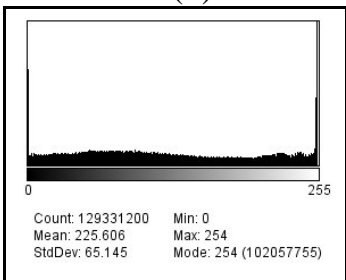

(e)

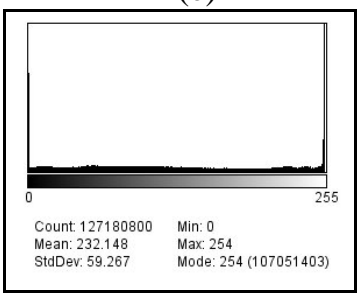

(g)

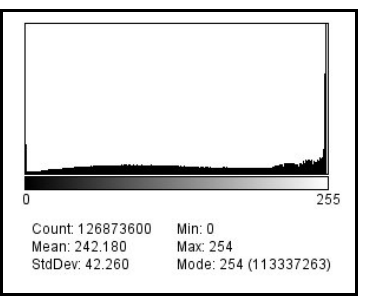

(c)

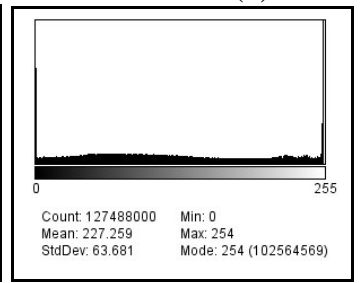

(f)

Gambar 5 Histogram citra speckle pada intensitas rata-rata video

Gambar 5 merupakan histogram video yang menunjukkan distribusi intensitas secara merata dimana sumbu horizontal merupakan distribusi piksel dan sumbu vertikal merupakan frequency count pixel. Distribusi intensitas secara merata menunjukkan kualitas video yang baik karena memiliki penyebaran secara merata setiap derajat keabuan pixel (Erlangga, 2014).

Ukuran bulir spekel merupakan parameter yang penting pada sebuah pola spekel. Penentuan ukuran bulir spekel dilakukan dengan fungsi autokorelasi menggunakan software MATLAB. Ukuran bulir spekel masing-masing frame dihitung dan dirata-ratakan.

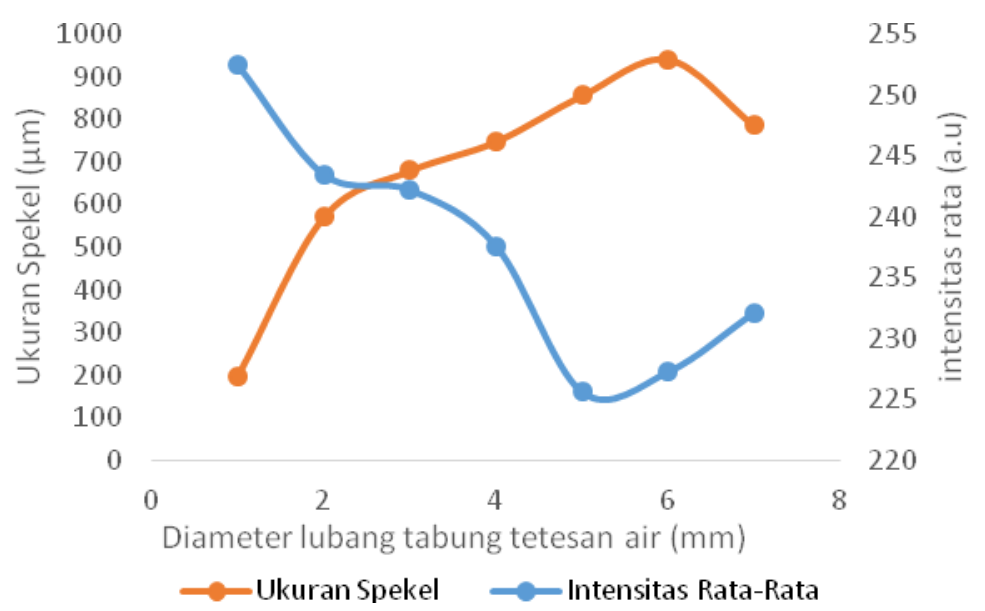

Gambar 6 Nilai intensitas rata-rata video dengan ukuran bulir spekel terhadap tetesan air

Gambar 6 memperlihatkan bahwa korelasi ukuran bulir spekel dan nilai intensitas ratarata pada variasi tetesan air memiliki kecenderungan hasil yang berbanding terbalik. Saat intensitas rata-rata video makin kecil maka nilai ukuran spekel akan semakin besar. Semakin kecilnya nilai intensitas rata-rata menunjukkan berkas cahaya yang sampai ke CCD tidak sampai secara penuh. Hal ini dikarenakan berkas cahaya terhambur ketika tetesan air melewati berkas cahaya. Hamburan ini direkam oleh CCD sehingga menghasilkan citra spekel yang terlihat seperti tertutup oleh sebuah bayangan yang menyebabkan semakin kecilnya nilai 
intensitas citra. Jika bayangan yang direkam oleh CCD semakin besar maka akan semakin besar juga ukuran bulir spekel. Hal ini konsisten dengan temuan Chicea (2007) yang mengatakan bahwa ukuran bulir spekel kecil ketika hamburan cahaya yang ditangkap lemah. Ukuran pola spekel juga tergantung sudut maksimal antara sumber dengan detektor cahaya berpengaruh besar juga terhadap ukuran spekel, jika nilai sudut besar, maka ukuran spekel yang dihasilkan kecil (Chipouline, 2011).

Pada Gambar 6 terlihat adanya data yang kurang linear yakni pada tetesan air pada tabung berlubang $6 \mathrm{~mm}$ dan $7 \mathrm{~mm}$. Hal ini disebabkan oleh area lubang pada alas tabung untuk jatuhnya tetesan air lebih luas dari pada area jatuhnya tetesan air pada tabung $1 \mathrm{~mm}-5 \mathrm{~mm}$ yang memiliki area jatuh yang lebih kecil. Pada tabung $6 \mathrm{~mm}$ dan $7 \mathrm{~mm}$ jatuhnya tetesan air tidak teratur dan tidak seluruhnya melewati berkas laser yang menyinari CCD sehingga tidak terekam seluruh kejadian tetesan air yang jatuh. Hal ini juga mempengaruhi ukuran bulir spekel.

\section{KESIMPULAN}

Berdasarkan hasil penelitian ini, maka dapat ditarik beberapa kesimpulan yaitu citra spekel tetesan air dapat dihasilkan menggunakan metode LSI, nilai intensitas citra spekel berbanding terbalik dengan ukuran bulir spekel, semakin kecil nilai intensitas citra spekel maka ukuran bulir spekel semakin membesar disaat tetesan air pada tabung berlubang membesar.

\section{DAFTAR PUSTAKA}

Chipouline, A., 2011, Spatial Noise and Speckel, abbe School of Photonics, Freidrich-Schiller Universitat

Chicea, D., 2007, Biospekcle Size and Contras Measurement Application in Particle Sizing and Concentration Assessment, Romania Journal Physics, Vol. 52, Nos. 5-7, P. 625-632

Erlangga, A.R., 2014, Analisis Kontras Spekel Pada Oli Mesran SAE 20W-50 Terhadap Perubahan Kekentalan Dengan Variasi Temperatur Menggunakan LSI , Skripsi, FMIPA, Unand, Padang

Harmadi, 2012, Analisis Pola Spekel Akusto-Optik untuk Pendeteksian Vibrasi Akustik pada Dental Plaque Biofilm, ,Jurnal Fisika Aplikasi (JFA), Vol.8, No. 1, hal. 1 - 6

Kolte, G. dan Ghonge, P.A., An Image Processing Based Raindrop Parameter Estimation, International Journal Of Engineering trens and Technology (IJETT), Vol.31, No. 2, hal. $73-77$.

Loffler-Mang, M. dan Joss J., 2000, An Optical Disdrometer for Measuring Size and Velocity of Hydrometeors, Journal of Atmospheric and Oceanic Techology, Vol. 17, hal. $130-$ 139.

Marzuki, Kozu, T., Shimomai, T, Hashiguchi, H., Randeu, W. L., dan Vonnisa, M., 2010, Raindrop Size Distribution of Convective Rain over Equatorial Indonesia During the First CPEA Campaign, Atmospheric Research, Vol. 96 hal. 645 - 655.

Marzuki, M., Hashiguchi, H., Yamamoto, M.K., Mori, S., dan Yamanaka, M.D., 2013, Regional Variability of Raindrop Size Distribution Over Indonesia, Annales Geophysicae, Vol.31, hal. 1941 - 1948

Muchlian, M., 2013, Analisis Pola dan Ukuran Bulir Spekel menggunakan LSI (Laser Speckle Imaging) pada Lapisan Tipis TiO2, Jurnal Fisika Aplikasi (JFA), Vol.9, No. 2, hal. 52 56.

Permana, R.G., Rahmawati, E., dan Dzulkiflih., 2015, Perancangan dan Pengujian Penakar Hujan Tipe Tipping Bucket dengan Sensor Photo-Interrupter Berbasis Arduino, Jurnal Inovasi Fisika Indonesia, Vol.4, No. 3, hal. 71 - 76

Rabal, H.J., and R.A Braga, 2009, Dynamic Laser Speckel and Application, Optical science and engineering: 139, Taylor \&Francis Group, LLC

Sawant, S., dan Ghonge, P.A., 2015, Estimation Of Rain Drop Analysis Using Image Processing, , International Journal Of Science and Research, Vol.4, hal. 1981 - 1986

Tamaki, Araie, Kawamoto, Eguchi, dan Fujji, 1994, Non-contact, Two Dimension Measurement of Retinal Microsirculation Using Laser Speckel Phenomenon, Invest Ophthalmol Vis Sci, 35, hal. 3825-34. 
Wang, Y., Zhao, P., Gao, W., dan Chen, X., 2014, Optimization of forward-scattered light energy and de-coherence of Mie scattering for speckle suppression, Opt Quantum Electron, North University of China 